\title{
The Impact of Research in Pediatrics on the Health of Children
}

\author{
RICHARD B. JOHNSTON, JR. ${ }^{(14)}$ \\ Department of Pediatrics, National Jewish Hospital and Research Center and University of Colorado School of \\ Medicine, Denver, Colorado, USA
}

As one anxiously ponders the formidable task of preparing this address, deriving a suitable title becomes particularly important. Consider the plight of the New York Times, which innocently printed the title of a daytime television show for housewives as, "I Stand Here Ironing." What must have been an impressive response by some of their more "liberated" viewers prompted a hasty retraction, and revision of the show's listing to "Inner Landscape" (9)-a beautiful recovery. My title, though perhaps not so profound, is, I hope, more descriptive.

Much of what I will say could be said by many of you; and while I am addressing you, I am directing many of my remarks to those who are not here, to those in pediatrics who feel little commitment to research. An additional word about the title by way of definition: "Research in Pediatrics" here is meant to refer to research done by pediatricians in their laboratory or office, or research done by anyone in the general environment of a department of pediatrics. It is not necessary in the context of this address that the subject of the research be children or diseases peculiar to children. One last introductory comment: This address offers few data. Rather, you will hear opinions and some suggestions for change, along the lines of comments between friends who share common ambitions and suffer common frustrations.

Some of the benefits of research in pediatrics are outlined in the table. All are rather obvious. Item 1 is particularly so, and little more needs to be said here about the many specific benefits to our children's health that have been derived from basic and clinical research. It is worth repeating, however, that the discovery of polio vaccine has been estimated to save the United States more money each year than the entire medical research budget (3). The fact that most of us have not been involved in quite such notable advances does not diminish the contribution that can be made to the health of children by each publication of high quality that is related to the fetus or child, or to any of his constituent cells or molecules.

The beneficial effects of research on the clinical care of children and on the teaching of pediatrics (Table 1, item 2) are not quite so apparent and can be easily overlooked. Benefits of this nature are bestowed first on the physician and, through him, on his patients, or on the residents, fellows, or students whom he wishes to teach. As you consider the arguments that follow next, please understand that I do not mean to say that one must do research in order to become the complete pediatrician or the persuasive educator. All of us know expert clinicians and inspiring teachers who had little if any experience in research.

A fundamental attitude with which one commonly undertakes research is a dissatisfaction with the status quo. In medical research, this takes the form of dissatisfaction with inadequate diagnostic capability, ineffective treatment, or insufficient understanding of the disease process. In general, the researcher assumes that the current state of knowledge is unsatisfactory. As the experiments proceed, even the doctrines upon which the field is based may be questioned. Thus, by its very essence, research is critical of existing practices. The young physician imbued with this attitude is better prepared, I believe, to enter a profession in which the factual base required for practice constantly changes; he recognizes the need for change and can be excited by the acquisition of new knowledge. The teacher dissatisfied with today's science sensitizes his students to the existence of factual inadequacies and facile assumptions and prepares his students to seek the new understanding that will be needed to practice the new medicine.

Participation in research-at least, in research that dissects basic processes of physiology or pathophysiology - can have a second major effect on a physician's thinking and on his approach to patients. Namely, it can train him to analyze his patients' problems from the standpoint of the steps in their pathogenesis. Immanuel Kant, who died in 1804, remarked that, "Physicians think they do a lot for a patient when they give his disease a name" (5). I suspect that most of us two centuries later are no less delighted in ourselves when we can pin a label on our patient's illness. In fact, the less we understand the disease process, the more elated we are at being able to name it. Such satisfaction in labeling, however, perpetuates our ignorance and decreases our chances of finding out what led to the illness, how severe it really is, and how the patient's body has reacted to it (6). The pediatrician disciplined through research to analyze basic mechanisms is less likely to comfort himself with labels.

Participation in good research of any sort should teach the pediatrician such sound principles of experimentation as what constitutes good controls, how big the sample size should be, and whether a "statistically significant" difference is biologically meaningful, whatever the statistics say. Although clearly important to the quality of any research that he might complete, the acquisition of such principles, unfortunately, will not guarantee the success of his experiments. Never mind. In the least, it is highly likely that any naivete he may have had regarding the medical literature will be replaced by skepticism of everyone else's papers. That is, he will have improved his capacity to discriminate between good and bad research, certainly an important achievement for any clinician or teacher.

Incidentally, I wonder why we have been allowed by real writers to refer to our scientific inscriptions as "literature." Surely this is a euphemism, akin to using "mixologist" instead of "bartender," bootician" for "bootlegger," or "fountaineer" instead of "soda jerk" (7).

Experience with research can change a physician's attitude in a fourth major way. Having conveniently forgotten the errors of my early professional life, I am amazed now to note that, given a disagreement between a probable diagnosis derived from history and physical exam and one indicated by a lab test, a resident will side with the lab results most of the time. One way to learn fast the folly of such a habit is to do laboratory research. Any assay will do, but some are better than others. If a second tube is added to a one-tube experiment, the chances of error double. And so on in geometric progression, so that even after a great deal of experience, one continues to learn the hard way that the points at which a lab test can be adulterated, at least on occasion, are nearly infinite. Thus, research experience teaches us clearly that "caveat 
Table 1. Some benefits of research in pediatrics

1. Actual products of the research
II. Improvements in the practice and teaching of pediatrics
Participation in good research:
1. Inculcates dissatisfaction with the status quo
2. Trains the physician to consider mechanisms of pathogenesis
rather than to satisfy himself with labeling
3. Sharpens critical analysis of the medical literature
4. Induces healthy skepticism of laboratory results
III. The experience itself

emptor" should be stamped on all lab reports, and that we should be reassured that it is not yet time to replace the doctor with a computer. We might also be reminded that the need for a sensitive history and careful physical exam is greater than ever in the face of the current profusion of proffered diagnostic tests.

In summary, then, through participation in research the young pediatrician has an opportunity to acquire a dissatisfaction with the status quo in clinical medicine, a discomfort in attaching simplistic labels to his patients' diseases, a disdain for the bad paper, and a distrust in the clinical laboratory as the fountainhead of diagnostic truth. Thus, we could graduate restive skeptics who show little respect for present dogmas and who are primed to make substantial changes in the practice of medicine-an exciting prospect! What lecture series, journal club, or clinical elective can impart as effectively such critically important attitudes for the perpetual student and for the future leader of either clinical or academic medicine?

A final potential benefit from research (item III) is referred to here as "the experience itself." What is meant, more specifically, is the personal fulfillment that can be attained from participation in research. Fulfillment from the experience is admittedly distant from any direct impact on the health of children, but it plays a role that is fundamental to the more direct effects of research in that it is the driving force from which the fruits of the endeavor are derived. It would be presumptous of me to describe to this group the personal gratification that can come from research. Some may never perceive it; and for those who do, this sense of achievement takes different forms. For Hans Zinsser, research was an adventure-..... one of the few sporting propositions left for individuals who feel the need of a certain amount of excitement" (11). Gregory expresses a similar point of view: "Much of research is a kind of play activity: a game against Nature and sometimes a game against one's colleagues and rivals ..." (4). Lewis Thomas is optimistic: "There are probably no questions we can think up that cannot be answered, sooner or later, including even the matter of consciousness" (10). For Thomas there is something fundamental, natural, and intrinsically correct in the ambition that drives us to reach a comprehensive understanding of nature, including ourselves (10). Fulfillment, then, should derive from the discovery itself. For Bronowski, "The most powerful drive in the ascent of man is his pleasure in his own skill. He loves to do what he does well and, having done it well, he loves to do it better. You see it in his science" (2). For me, the personal rewards of research are a very real combination of the excitement of discovery and the satisfaction of creation. However meager one's disclosure, one can experience the exhilaration of seeing a small fragment of nature that no one has seen before; and during the slow, laborious, painful process of rearranging, cutting, adding, and rewriting the manuscript, one participates in an act of creation. Training in research can supply the pediatrician with the tools needed to pursue this fundamental curiosity and with the confidence to create, whether as a practitioner or academician.

I would like to turn now from opinions and philosophy to opinions and practicalities, and to conclude by addressing the question, "How can we support and strengthen research in pediatrics?" Many of you can respond to this question at least as well as I, and I hope only to remind you of some possible responses and to encourage you to undertake their application. Please note that in each case, the suggested response can be accomplished by us in pediatrics, without the need of political action, the help of outside groups, or an increase in available funding.

Those of you who first confronted research after completing clinical training will doubtless recall that the transition from the immediate, tangible rewards of caring for patients to the postponed, indefinite fruits of research can be difficult, even for the most disciplined individual. When confident of clinical skills yet unsure of success in teaching and research, the resident or fellow can become particularly attracted to the security of practice, especially if he retains a sizeable debt from medical school. Moreover, our sour faces and frequent complaints about too much work and too little funding obscure our expression of the compensations that sustain us in an academic career. One major source of difficulty that often faces the young pediatrician considering a research career is his lack of experience with the rewards of research. The problem is described aptly by the saying, "Those who hear not the music think the dancers mad" (1). Unless the tentative clinical investigator has experienced the excitement of discovery or the fulfillment of creating a finished publication, he is likely to think us mad-if previous observations had not already led him to the same conclusion. Thus, I would suggest that we consider the importance of developing opportunities for pediatric residents to participate in a supervised project that could result in a publication. This might be accomplished easily by review of the institution's experience with a particular disease, mode of therapy, or the like; but even short, well circumscribed laboratory projects are possible during an undisturbed elective. Along similar lines, in order to encourage the entry of particularly promising residents into research training, it should be possible to substitute clinical experience during subspecialty training for the third year of residency. It is not widely recognized that the American Board of Pediatrics will, in fact, permit such a "special alternative pathway" toward certification if the department chairman can argue convincingly that the candidate has demonstrated exceptional pediatric knowledge, clinical judgment, and technical and interpersonal skills (8).

Parenthetically, we might also recruit more effectively if occasionally we stopped voicing uur discontent about academic life long enough to say to ourselves and to our trainees, as Mark Twain is alleged to have said about Wagner's music, "It is not as bad as it sounds"- the excitement and challenge are worth the effort.

One obvious means of promoting better research in pediatrics is to require all postdoctoral fellows to participate in research of substance and quality. This should not need to be said; but, in fact, many pediatric subspecialty programs do not require that the fellow experience research in any meaningful way, usually because of overriding demands to deliver patient care. The substantial research project would not necessarily call for the use of pipets or animals; but a case report should not suffice. Of course, preparation to become an independent investigator capable of competing successfully for research funds demands a full commitment-at least 2 years of full-time research training, or its equivalent prior to fellowship.

In order to educate fellows to quality research and residents to a critical dissection of clinical problems, each training program must have at least a few faculty members who possess a drive to explore basic mechanisms of physiology or disease. This is, of course, not a new concept, but one espoused by American medical schools since the Flexner report of 1910. Unfortunately, some pediatric postgraduate programs have played lip service to maintaining a balanced faculty, and the threat of having to earn salaries through patient care stresses further this balance. The young researcher seeking his first job should be encouraged to negotiate strongly for protection of his time; and senior faculty and the chairman should remain sensitive to the researcher's continuing need for time to do experiments, think and write. This arrangement carries the clear obligation, on the other hand, of using such time productively.

Pediatric journals represent the discipline of pediatrics to the rest of the world. Most members of the Society for Pediatric 
Research and the American Pediatric Society have a particular interest in the journal Pediatric Research. In the least, we must subscribe with our dues, and the assumption is widespread among us that the journal should represent the scope and quality of the best research produced by the pediatric academic community. Most would agree that the quality of this publication has steadily improved since its founding 14 years ago. As the breadth, sophistication, and size of the journal have increased, however, the editorial structure of the journal has become an anachronism. Unless changes are made, this structure could become an impediment to further progress. The following suggestions for change have been discussed in full with the current Editor-in-Chief, Dr. Joe Bellanti.

First: Submitted papers should be processed, not by a single editor, as at present, but by a chief editor and a local board of several associate editors representing different biomedical disciplines. Maintaining a grasp on the technology and body of knowledge associated with the various fields of medical science simply exceeds the capabilities of any one editor, even Dr. Bellanti, who was burnished by the rigors of immunology. An editorial board that convened regularly could select the most appropriate referees for papers in a field, critically evaluate referees' comments, assist in improving the journal's standards of quality for writing, and offer a confidence, perspective, and prestige to the review process that no one or two editors could possibly confer. Second: The editor and associate editors should be compensated for their time-by salary, a grant to their research, travel funds, or the like. Such compensation is now customary for most biomedical journals. This could necessitate an increase in membership dues, but the return should easily justify the modest investment that would be needed. Third: The journal's chief editorship and the location of its board of associate editors should be rotated among pediatric institutions of excellence at regular intervals - of, say, 4 to 6 years. This would reduce the chances of "burnout" by the editors and staff, regularly seed the journal with fresh ideas and enthusiasm, involve more people through the years in the health of the journal, and allow the editor and board to move on to other challenges. I would suggest that the first board be established in the Washington-Bethesda area, with Dr. Bellanti as editor, which would facilitate transition. Finally: Pediatric Research is owned by the International Pediatric Research Foundation, Incorporated, and at present bears no apparent accountability to the research societies whose membership dues support it. Better communications between the societies and the journal's management are needed if society members are to develop full confidence in the journal and an enthusiastic sense of responsibility for its strength. As at least a first step, one or both of the two representatives from each research society to the presently structured editorial board might sit as regular members of that society's council.

My last suggestion relates to the role of the pediatric research societies in supporting research in pediatrics. In my opinion, whatever political or other tasks the societies undertake, their fundamental, continuing responsibility is to foster superior research by pediatricians. This meeting constitutes the principal means by which that can be accomplished. Thus, the papers presented here should represent the very best work in pediatrics if we are to excite young pediatricians to the active pursuit of careers in research and, perhaps more to the point, if we are to influence the substance and quality of their work. We must consider it important to submit good work here; and, in turn, the societies must recognize excellence, whatever the nature of the work, basic or clinical. This meeting must be a proper forum for all pediatric investigators, including those whose research competes with the best work of basic scientists, internists, or any other group.

This is also the only national meeting that convenes clinical investigators across the breadth of pediatrics. The unique opportunity to gain new knowledge from pediatricians in other subspecialty areas and to address problems of general concern to academic pediatrics needs to be preserved. The proposal that subspecialty clubs convene during time now allocated to the general meeting deserves consideration; but the possible advantages of changes like this must be weighed cautiously against any possible loss of the unique opportunities afforded by the functions of the full societies.

It is likely that most of us went into pediatrics because of a basic love of children, a concern for their problems, and a hope for their future as our successors. Although perhaps at times forgotten, it seems unlikely that these motives were abandoned when we entered research. I have tried to remind you of several ways in which research carried out in a pediatric environment can have an impact on the health of our patients. In addition, if we are vigorous in our support of research, if Pediatric Research - and, as importantly, other pediatric journals-transmit important new thoughts and clear thinking, if the papers presented at this meeting reflect the best work from pediatrics, then the new challenges in social or biomedical science can be portrayed as relevant to normal development or to the afflictions of children, and we can attract the brightest minds to our discipline and advance the talent that we already hold. We must convince all those in leadership that an active, strong program in research is an integral and essential component of any serious effort to meet our responsibility as pediatricians for the health of children.

\section{REFERENCES AND NOTES}

1. Anonymous: Nat. Geog., 153: 692 (1978)

2. Bronowski, J.: The Ascent of Man. p. 116 (British Broadcasting Corp., London. 1973).

3. Funder, J.: All really great lies are half true. Science (Wash. D.C.), 206: 1139 (1979).

4. Gregory, R. L.: Concepts and Mechanisms of Perception. p. 13 (Duckworth, London, 1974).

5. Kant, I.: In: M. B. Strauss: Familiar Medical Quotations. p. 95 (Little, Brown and Co., Boston, 1968).

6. Lipkin, M.: The CPC as an anachronism. N. Engl. J. Med., 301: I113 (1979).

7. Menken, H. L.: Euphemisms. In: The American Language pp. 284-300 (Alfred A. Knopf, Inc., 1965).

8. Prospective Petition for Special Alternative Pathway. (American Board of Pediatrics, Inc. Chapel Hill, NC, 1980).

9. The New Yorker (citation). p. 105. September 8. 1980. ("I Stand Here Ironing" title of a short story by $T$. Olsen).

10. Thomas, L.: Hubris in science? Science (Wash. D.C.), 200: 1459 (1978).

11. Zinsser, H.: In: M. B. Strauss: Familiar Medical Quotations, p. 504 (Little, Brown and Co., Boston, 1968).

12. Presidential address, Society for Pediatric Research, San Francisco, CA, April 30. 1981 .

13. The author is grateful to Drs. A. Christie, M. D. Cooper, P. M. Henson, A. R. Lawton, C. D. May, R. E. Merrill, and F. S. Rosen for constructive provocation. and to Drs. J. W. Benton, A. Robinson, S. W. Sell, M. T. Stahlman, and J. L. Shapiro for support, during the evolution of the perspectives expressed here.

14. Requests for reprints should be addressed to: Richard B. Johnston. Jr., M.D., National Jewish Hospital and Research Center, 3800 East Colfax Avenue. Denver, CO 80206 (USA). 